\title{
Entrevista a Enrique Tandeter
}

Carlos Marichal

EL COLEGIO DE MEXICO

$\mathrm{E}$ ntrevista celebrada con Enrique Tandeter el 27 de septiembre de 1993 por parte de Carlos Marichal. La entrevista se efectuó en Buenos Aires, en el Instituto de Investigaciones Históricas Dr. Emilio Ravignani, del cual Enrique Tandeter es miembro. Es, asimismo, profesor de la Universidad de Buenos Aires e historiador connotado del periodo colonial. Su último libro es Coacción y mercado. La minería de la plata en el Potosí colonial, 16921826, Editorial Sudamericana, Buenos Aires, 1993.

Carlos Marichal: Me gustaría que nos hablaras sobre varios temas que se re. fieren a la historia económica y pensaba que podríamos comenzar con el tema del libro tuyo que ha publicado hace poco la Editorial Sudamericana sobre la minería colonial en Potosí. Por lo que nos dices en el prólogo, esta obra tiene una larga historia que arranca con trabajos y estudios emprendidos en la Universidad de Buenos Aires desde fines del decenio de 1960 , si no me equivoco.

Enrique Tandeter: El origen concreto del trabajo es una sugerencia de Ruggiero Romano a quien conocí en París en una situación de viaje, y quien insistió en lo sorprendente que resultaba que nadie hubiera utilizado los riquísimos documentos relativos a Potosí que se encontraban en el Archivo General de la Nación en Buenos Aires. Es decir, lo que él me estaba diciendo es que tenía en Buenos Aires uno de los mayores archivos bolivianos sobre la minería en el periodo colonial, cuyo papel dentro del espacio peruano era conocido y que era sorprendente que no se habían utilizado esos papeles para un estudio profundo de Potosí. La 
sugerencia inicial de Romano se refería a una de sus preocupaciones constantes en el tema de la circulación mone. taria y el interés de estudiar la circulación monetaria a partir de las acuñaciones de la ceca de Potosí. El periodo que cubrían esos documentos (que empecé a frecuentar apenas vuelto a Buenos Aires, a partir de 1970) era precisamente el del siglo XviII. A partir de las primeras exploraciones en Buenos Aires fui tentado a visitar Potosí, donde evidentemente cumplí con la primera indicación de Romano, que era reconstruir -como él lo había hecho para el periodo similar en la casa de Chile- el detalle de las acuñaciones monetarias potosinas. A hí me ocurrió algo bastante extraño después de una tarea labo. riosa, sin computadora portátil en aquella época, sin fotocopiadora, a mano, porque estamos hablando de una reconstrucción estadística donde tomaba día por día, rendición por rendición todas las acuñaciones por tipo de moneda entre 1750 y la década de 1820. Lo que hice fue simplemente su. mar las monedas al llegar a Buenos Aires, y ahí apareció una curva que me sorprendió, ya que era una curva de crecimiento sostenido de la acuñación de plata durante la segunda mitad del siglo XVIII. Me llamó la atención porque, efectivamente, el siglo XVIII no es la época más famosa de Potosí. Es una época que viene después del auge del siglo XVI y, también, según la visión convencional, después de la crisis del siglo XvII. Lo que me sorprendia era que ahí había una nítida tendencia al alza de la acuñación, que iba en contra de las pocas cosas que yo había leído de historia económica rioplatense en las que se aludía a la situación de Potosí y su relación con el virreinato del Río de la Plata, del cual, los territorios altoperuanos pasaron a ser parte a fines del siglo xviII. Naturalmente, esta discrepancia entre los saberes aceptados y esta estadística que yo había elaborado pacientemente, hizo que lentamente fuera abandonando el tema de la circulación monetaria y me metiera al tema lógicamente previo de la producción minera. Y de ese tema de la producción minera ya no salí más en los 20 años en que trabajé en este libro. Sin embargo, el periodo no tiene que ver sólo con el azar de los documentos, sino que también tiene que ver con el origen "argentino" de mi ubicación en el momento de comenzar el trabajo. Me interesaba un Potosí cuya producción minera era el telón de fondo del proceso "tardío-colonial" que, a su vez, era obviamente el acto previo del drama de la independencia. Era de eso de lo que se trataba.

C.M. El virreinato de Buenos Aires era el lugar a través del cual, o hacia el cual, iba la mayor parte de la plata altoperuana desde 1778 ¿o no?

E.T. Sí, pero no sólo eso, pues hay que entender -como después sería apuntado en algunos trabajos de Hebert Klein, pero sobre todo ampliamente explicado en un libro de Tulio Halperín-, que la creación del virreinato fue una creación extremadamen. te artificial, que fue posible porque las finanzas estatales fueron artificalmente ligadas al excedente estatal producido en Potosí. Es decir, había una doble relación: por un lado, la relación entre importación de mercancías europeas y pago con moneda acuñada en Potosí 
(con todas las intermediaciones de la circulación interior); y, por otro, el tema unidireccional del excedente esta. tal del Alto Perú a Buenos Aires, que sostenía esta nueva creación estatal y, eventualmente también en momentos excepcionales, llegaba a canalizar algo de ese excedente hacia la metrópoli.

C.M. En el trabajo describes en detalle el papel de ciertos comerciantes que controlaban estos flujos entre Potosí y Buenos Aires. Hablas también del manejo de los "situados", es decir, de las remesas de plata por cuenta de la Real Hacienda. Pero te pregunto: ¿la mayor parte de la plata que salía de Potosí para Buenos Aires era en con. cepto de remesas privadas o públicas?

E.T. No, la mayor parte de las remesas eran definitivamente privadas, aunque las públicas eran sin embargo muy abundantes, suficientemente abundantes -insisto- como para sostener la estructura civil y militar bastante compleja que se instala en ambas márgenes del río de la Plata a fines del siglo XVII, en un lugar que es un lugar de avanzada del imperio español donde hubo un enfrentamiento con el imperio portugués firmemente asentado en el territorio brasileño.

C.M. En el caso de de la Real Hacienda de México, para el siglo XVIII tam. bién se observa su papel como sostén de las finanzas de una zona muy amplia que iba más allá del virreinato de Nueva España, incluyendo al Gran Caribe. O sea, ¿podría afirmarse que a través del estudio de los flujos de plata de la Real Hacienda, se puede llegar a entender mejor la relación que existía entre grandes regiones del imperio español?

E.T. En el caso Potosí y del río de la
Plata, como he demostrado con un grupo de colegas en otros trabajos, la relación es más compleja. Ello es así porque es diferente la relación estatal donde la dirección es clara, y esto desde antes de la creación del virreinato en 1778. O sea, ya desde mediados del siglo XVIII hay, precisamente por estas razones militares, un curso de los fondos excedentes estatales desde el Alto Perú al río de la Plata; pero, desde el punto de vista privado, esa articulación de la región altoperuana con una región más amplia mantiene muchos de los rasgos de las primeras redes que nos marcó Assadourian para el momento del auge del siglo XVI. Si bien en el comercio potosino se han cortado las vinculaciones directas con algunas de las zonas más alejadas de lo que Assadourian llamó "el espacio peruano" -por ejemplo el actual Ecuador, o buena parte de Chile-, Potosí mantiene sin embargo un poder articulador muy alto de todo lo que es el "sur andino" y el río de la Plata. Y me parece muy interesante decir que, desde el punto de vista privado, Potosí cumple un papel tan fundamental para el sur andino como para el río de la Plata. Y muchos comentarios de la época insistían en el papel fundamental de la plaza potosina porque es en este mercado donde se colocaban la mayor parte de los excedentes de producción, fundamentalmente vitivínicolas, pero también de azúcar y textiles de la región del sur peruano. Es decir, este mercado "externo" que quedó dentro de los límites del virreinato peruano seguía cumpliendo una función esencial en el juego de la balanza comercial del Perú.

C.M. ¿Podrías precisar un poco más 


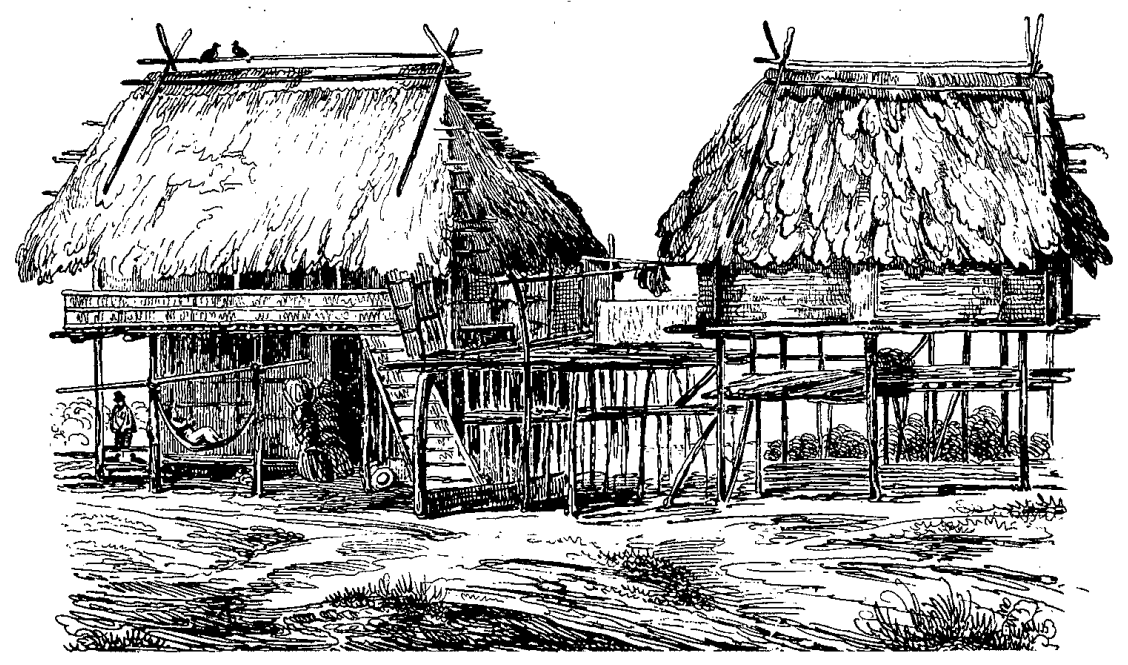

la importancia y el carácter geográfico específico de algunos de los flujos más importantes? Esto lo pregunto porque tiene interés para el caso de Nueva España, ya que los estudios de carácter regional ahí están poniendo cada vez más énfasis en el problema de los flujos "interregionales", y no sólo intrarregionales.

E.T. Los flujos más importantes desde el punto de vista del comercio de mercancías americanas tienen que ver con el abasto al mercado de Potosí de los tejidos y azúcares de la región de Cuzco y del vino, pero sobre todo de aguardiente de uva de la región de Arequipa en el sur del Perú; y, por otra parte, hay una serie de zonas de adentro del Alto Perú que contribuyen muy signficativamente a la provisión de los mercados altoperuanos, tanto en tubérculos como en granos, así como en los tejidos más bastos de algodón y otros productos menores como jabones, maderas, etc. En cambio, Buenos Aires tiene un papel crecientemente monopólico a lo largo del siglo XVIII en la provisión de los mercados altope. ruanos de mercancías importadas, incluyendo los insumos para el proceso minero como lo eran el mercurio y el hierro.

C.M. Había también un comercio re. lativamente importante de otros productos, como por ejemplo de mulas o de yerba mate, ¿no?

E.T. Efectivamente, aunque debe tenerse en cuenta que el comercio de mulas había decaído mucho para fines del siglo XVIII, siendo un comercio que 
vinculaba a la zona altoperuana con el noroeste del actual territorio argentino. El comercio de yerba mate, por su parte, se da con el Paraguay a través del actual litoral argentino, pero no es un comercio extremadamente importante en los mercados locales consumidores altoperuanos. Pero aquí hay que hacer una distinción. En la segunda mitad del siglo XVIII, lo que se ve es que, como consecuencia de una serie de políticas estatales, los mercados tienden cada vez más a convertirse en mercados consumidores no intermediarios. Esto es resultado del aumento en la cobranza de la alcabala, las prácticas de imposición de la doble alcabala o, lo que es lo mismo, la imposibilidad de ir postergando el pago de la alcabala, frente a funcionarios ávidos, hasta el momento del consumo final. $Y$ esto hizo que los comerciantes dividie. ran sus partidas y las dirigieran lo más precisamente posible a los mercados finales consumidores. Ello determinó cambios en la actividad de Potosí, que en algún momento del siglo XVII (y aparentemente también a comienzos del xviII) había jugado un papel importante como plaza redistribuidora. Ciertos flujos, por ejemplo de la yerba mate, que tenían una cierta tendencia a estar controlados por pocos individuos, en la medida que como origen tenían a los jesuitas como únicos grandes productores, recorrían un camino fijo y tenían como una de sus grandes etapas Potosí, pero no como centro consumidor sino como etapa de una siguiente redis. tribución. Esto desapareció en la segunda mitad del xVIII. Entonces ahí, los datos que tenemos para la segunda mitad del XVIII se refieren más al consumo que excluye normalmente esta redistribución, que por supuesto se sigue dando, pero sólo en casos de gran saturación del mercado donde no queda más remedio que volver a reexportar la mercancía a un lugar donde se pagara segunda alcabala, pero por lo menos donde existía la posibilidad eventual de venderlo. Esto explica un poco la caída en mi valoración respecto a unas cifras conocidas de Garavaglia, por ejemplo, sobre el papel de la yerba mate en el Alto Perú a comienzos del siglo XVIII donde, en realidad, Potosí aparece en mi criterio agrupando lo que va a ser el consumo de toda la región. En cambio, para fines del siglo, nuestros datos ya se refieren más precisamente al consumo.

C.M. Es muy interesante este problema de la importancia del papel de redistribuidor de Potosí a través del tiempo. Pero, pasando a otro tema, quiero preguntarte lo siguiente: A lo largo del texto, pero en particular al final de Coacción y mercado... estableces una serie de paralelos o, más bien, contrastes entre las minerías de Potosí y la de Nueva España en el siglo xvIII. Señalas, entre otras cosas, las características que tiene la minería de Nueva España en el xvill en función de una mayor tasa de crecimiento global -quizá con picos más abruptos- y en cambio un proceso más lento de crecimiento o de recuperación de la minería en el Alto Perú y específicamente en Potosí. ¿Cuáles son las causas de estas diferencias? Evidentemente es imposible rela. tarlas todas, pero me gustaría que puntualizaras algunas de las causas de aquellas diferencias.

E.T. Las diferencias en términos de 
estadística de la producción minera novohispana, comparada con la producción particular de Potosí, son las que acabas de resumir muy bien. Es decir, en Potosí lo que hay es un crecimiento limitado que se ubica en la segunda mitad del XVIII. Hay una tasa extremadamente regular de crecimiento en torno al $2 \%$ anual frente a una tasa muy variable, como la que se aprecia en las estadísticas elaboradas más recientemente para el conjunto de Nueva España, que muestran momentos de máximo crecimiento a comienzos de siglo y nuevos momentos de alza a finales de la época borbónica. Lo que más me interesa de este contraste entre picos y valles que hay en México a lo largo de un periodo muy prolongado y esta suavidad del crecimiento potosino, es que me sirve de entrada a lo que son las enormes diferencias en la estructura productiva de la mayoría de los centros novohispanos del xvin y Potosí, tomado como caso de comparación particular. Yo diría que esas diferencias (y aquí voy a ser muy esquemático -enormes espero y creo que el libro es más sutil y matiza más- pero en definitiva me gusta ser extremoso, porque creo que el sentido de este contraste es revelar las diferencias) se relacionan con un problema de organización empresarial. El problema de la organización empresarial tiene que ver con la existencia en Nueva España de empresarios que arriesgan, es decir, invierten con inseguridad acerca de cuándo van a recibir una recompensa por su inversión y cuán grande va a ser ésta. Son muy conocidas las historias de los trabajos de desagote, los trabajos de tunelización, etc., que se dan en Nueva
España, algunos de los cuales implican décadas de trabajo sin ningún resultado. Es decir, era frecuente que quebrara el padre, aunque quizá tuviera mejor suerte el hijo o simplemente otro empresario que continuaba. En el conjunto de las historias empresariales de Nueva España son más los empresarios que no ven en su propia vida los resultados positivos que los que sí los ven. En el caso potosino, la aventura minera es de un carácter totalmente distinto. Para entender esto hay que retomar los elementos que el libro resalta más: que existía una estructura tripartita, en la cual la propiedad de la vida productiva estaba en manos de un dueño general ausentista, mientras que la gestión de la empresa estaba en manos de un arrendatario que era el que controlaba a la fuerza de trabajo, tanto en su sector coactivo como en el libre. Este empresario-arrendatario era un aventurero que no tenía capital y al que la situación misma del proceso productivo le facilitaba poco que se arriesgara en inversiones de largo o aun de me. diano plazo. La opción que el arrendatario potosino tenía era simplemente la rapiña: rapiña de corto plazo de las minas y, sobre todo, rapiña del trabajo forzado predominante en Potosí. Si en un esquema muy rápido tuviese que explicar las diferencias entre Nueva España y Potosí en el terreno de la organización empresarial, diría que la clave reside en la prolongación de las estructuras en el trabajo coactivo que el Estado colonial garantizaba a los empresarios altoperuanos desde fines del siglo XVI. Creo que es la continuidad de esta migración enorme de trabajadores forzados rotativos lo que explica, prime- 
ro, la separación entre propiedad y gestión de la empresa y, segundo, por mecanismos que están muy detallados en el libro, porque el arrendatario veía siempre coartadas sus posibilidades de acumulación, veía en riesgo su estabilidad al frente de la empresa y, por lo tanto, veía siempre desestimulada su eventual inversión en el mismo tipo de tareas que movian los capitales y energías de los empresarios novohispanos, es decir, desagües, túneles, obras interiores. Yo creo que muy esquemáticamente de esto se trata.

C.M. Pero, de hecho, los empresarios mineros potosinos tenían una cierta ventaja aparente en tanto contaban con una mano de obra forzada. Es. tás hablando de la mita y de los mitayos. Creo que el trabajo centra mucha atención en este tema que para la minería mexicana es, digamos, muy diferente.

E.T. Si, pero en este sentido mi libro es muy tradicional en tanto retoma la idea que se pude encontrar en algún artículo razonablemente antiguo, como la excelente síntesis que Brading y Cross dedicaran hace unos cuantos años al conjunto de la minería. O sea, en definitiva lo que estamos confirmando es que Potosí era distinto por la presencia de la mita. Pero escribir un libro para reiterar esto a través de más de trescientas páginas no era muy tentador. Lo que sí me tentó, y es algo que me parece distinto, se refiere específicamente a la siguiente pregunta. ¿Qué consecuencias tiene la existencia de una compleja estructura de recluta-

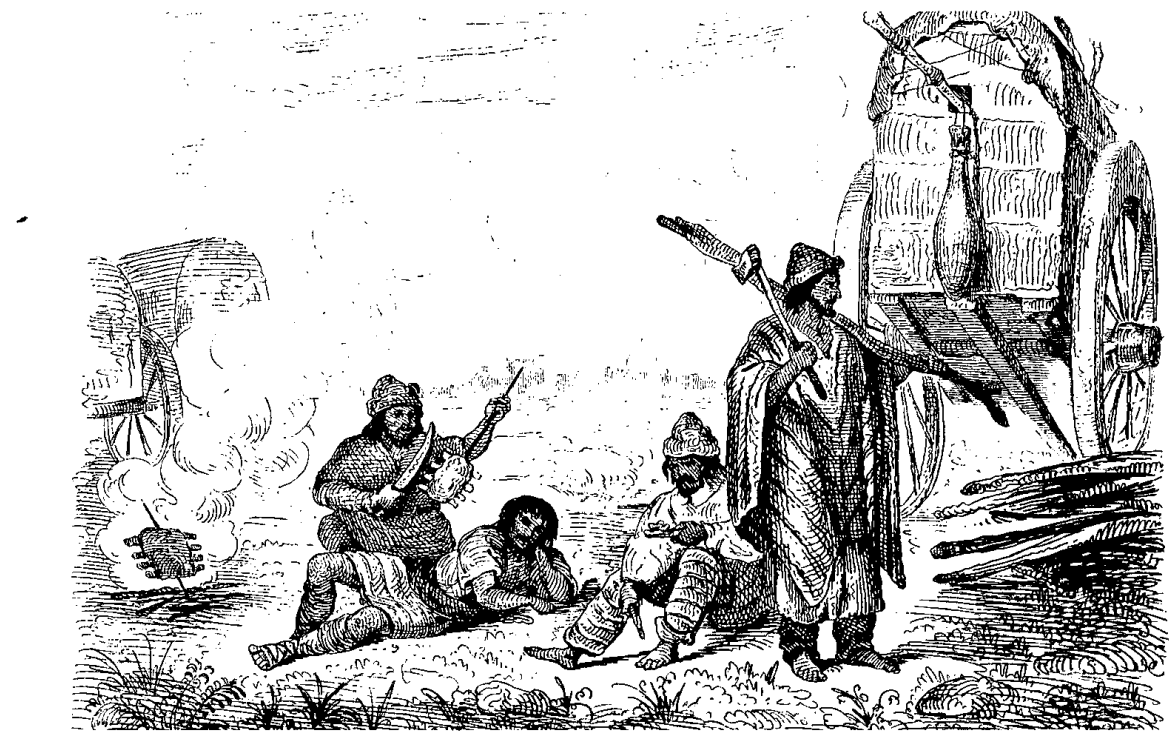

ENTREVISTA A ENRIQUE TANDETER 
miento coactiva de la fuerza de trabajo sobre la organización empresarial? Creo que este tema en realidad tiene algo que decirnos sobre aquellas antiguas discusiones acerca de feudalismo y capitalismo en América Latina. En definitiva, me parece que en el libro se dan elementos para entender por qué este tipo de trabajo coactivo tenía conse. cuencias. No era gratuito en el sentido de poder ser utilizado como cualquier otra forma de trabajo. Entonces mi conclusión es que este trabajo forzado tiene enormes ventajas en términos de rentabilidad para el conjunto de la industria pero que, a la vez, permite arreglos institucionales que llevan a que el excedente, que puede atribuirse a esta venta de trabajo, se divida de un modo peculiar entre el dueño ausentista y el arrendatario que corre efectivamente a cargo de la explotación. Además, como lo demuestra una gráfica en el libro, si cuantificamos (en cualquier año de la segunda mitad del siglo XVIII) la parte agregada del excedente del cual se apropian los arrendatarios por un lado, los dueños por otro, y la corona por su parte, descubriremos que los dueños más que duplican lo que se apropian los arrendatarios, y a su vez son superados aun por los beneficios inmediatos que la corona deriva mediante distintos impuestos, tanto a la producción minera como a la acuñación.

C.M. Ahora, esta diferencia que es muy notoria, y más notoria a partir de este libro, y que nos hace pensar más en el contraste entre dos formas de minería, implica que hay en cierto sentido un criterio diferente de los empresarios en Nueva España y de los de Potosí con respecto a la inversión.
E.T. Así es. Es decir, en Potosí ni los dueños ausentistas ni los arrendatarios tenían por qué invertir en tanto la reproducción de la industria estaba asegurada. Por un lado, estaba asegurada por la existencia de un yacimiento geológicamente único, ya que Potosí era un enorme yacimiento que era pobre en términos de riqueza o calidad de sus minerales, pero absolutamente masivo en cuanto a la cantidad, siendo en ese sentido inigualado. Por otro lado, la corona les había ofrecido un doble apoyo que consistía, en primer lugar, en asegurar la producción de trabajo forzado con base en toda la estructura coactiva, y en segundo lugar, en proporcionar el apoyo crediticio peculiar a Potosí, que estaba dado por la ayuda del Banco de San Carlos, el cual proveía buena parte del capital de giro con el cual efectivamente funcionaban estas empresas mineras durante la segunda mitad del siglo XVIII. En este contexto la inversión no era ni necesaria ni imprescindible para los dueños, ni para los arrendatarios. Por otro lado, no era posible para los arrendatarios, por su situación siempre al borde de la mera subsistencia o a la caída muy frecuente en situaciones de quiebra.

C.M. A hora, el aumento de la producción minera, que se da en la última parte de la segunda mitad del siglo XViII en Potosí, se puede medir tanto a nivel de la producción de plata como a nivel mercantil. Me parece que una forma de abordar este problema se encuentra en el estudio anterior, realizado con Nathan Wachtel, sobre precios, y más concretamente sobre precios y producción agraria en Potosí y Charcas en el siglo xviII. ¿Cuáles eran los 
objetivos de este estudio?

E.T. En el trabajo sobre los precios de Potosí, lo que buscabamos con Wachtel -siendo que ambos tenemos backgrounds académicos distintos, él con una tradición de estudios etnohis. tóricos centrados en el mundo indigena y en mi caso una preocupación ma. yor con la historia económica, la situación monetaria, la producción minera, etc.- era ver cómo las coyunturas po. dían verse en su movimiento en un mercado de gran tamaño como es el potosino. Entonces, con estos enfoques distintos, lo que queríamos ver era el conjunto de las coyunturas del mercado. De ahí nuestra preocupación por distinguir niveles distintos de mercancías: las locales, las regionales, las americanas, $y$ las extraamericanas en este mercado. Y, efectivamente, lo que descubrimos es que estos distintos grupos de mercancías, tenían movimientos disímiles y una historia que no pudimos explorar en su totalidad, yo creo que nunca se puede hacer en un trabajo específico de precios. Pero sí nos pareció interesante empezar nosotros mismos a reflexionar sobre el tema y ofrecerlo a la reflexión conjunta entre los colegas.

C.M. ¿El estudio era específicamen. te sobre el mercado de Potosí?

E.T. Sí, como en todos los estudios de precios, uno es muy prisionero de la fuente. En este caso tuvimos la suerte de encontrar estos libros de cuentas que se hallan en un convento de rigurosa clausura. Se trata de los libros de gastos de ese convento en un periodo muy prolongado que data desde 1676 hasta 1816, ofreciendo en la mayor parte de sus series una homogeneidad satisfactoria. Entonces elaboramos las series a partir de esto. Empezamos rastreando los precios de unos 200 productos y finalmente nos quedaron menos de 40 con una gran homogeneidad y continuidad que nos resultó acepta. ble, y son esos resultados los que hemos presentado en el trabajo.

C.M. ¿Entonces la base fundamental de ese trabajo fue la serie de precios a nivel de convento?

E.T. Respecto a los precios esa fuente fue la base exclusiva; aunque debo agregar que cuando hicimos el trabajo sólo teníamos un mínimo grado de confirmación acerca de su similitud con los precios, en algunas escasas fuentes aisladas del tipo de informes del estado del tiempo y de precios de los intendentes, que lamentablemente son muy pocos. Pero después de haber hecho ese trabajo, en otros trabajos - de los cuales uno acaba de ser publicado en el primer tomo de las Actas de la primera Reunión de la Historia de la Minería Latinoamericana celebrada en Zacatecas- correlacionamos algunas de estas series con series de precios obtenidas de los registros de la Aduana de Potosí, en mi investigación sobre las alcabalas. El resultado allí nos da finalmente mucha tranquilidad, en tanto hay un buen ajuste entre ambas series en el caso de que dispongamos de precios para productos análogos. El trabajo sobre precios tiene otra fuente importante que se refiere a la producción agraria, y es la fuente de los diezmos de Charcas deflacionados con un índice de precios que elaboramos en ese mismo trabajo.

C.M. Como complemento de los trabajos sobre minería y de éstos sobre 


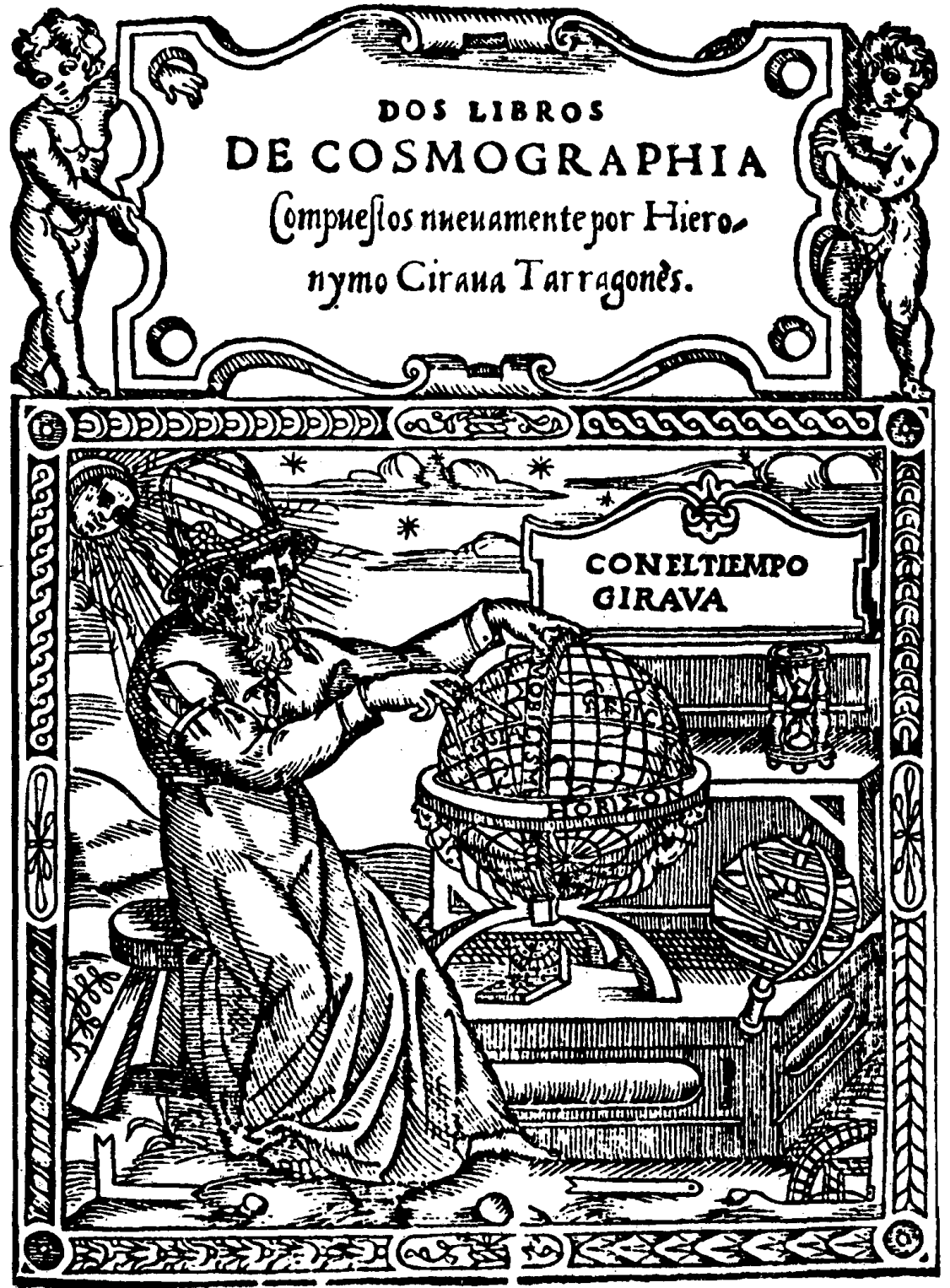


precios, has trabajado también los problemas de mercantilización y has hecho un estudio a partir de alcabalas, ¿no es así?

E.T. Sí, hemos hecho varios estudios y tenemos aún otros en carpeta para estudiar una fuente muy peculiar para el caso potosino que fue la de alcabalas. La peculiaridad no es nada más por la fuente, pues como sabes las alcaba. las existían en el resto del mundo hispano colonial, aunque en un sentido los registros alcabalatorios altoperuanos son inferiores a algunos casos novohispanos porque no incluyen ciertos productos menudos. Pero sí tiene una peculiaridad, y es que hemos podido comprobar que, en Potosí y en el periodo de nuestra investigación, es decir desde la creación de la Real Adua. na en 1779 , la alcabala afecta a todos aquellos productos que están legalmente gravados por ella, independientemente de quién sea el introductor de la mercancía. Es decir, en este periodo en Potosí no se aplica la exención de alcabala que desde comienzos de la co. lonia se aplicaba en la mayor parte de las colonias hispanoamericanas respecto de los tráficos que hacían los indígenas con sus propias producciones. No sabemos exactamente cuándo $\mathrm{y}$ por qué se tomó esta decisión en el caso potosino, pero hemos fundamentado una hipótesis, según la cual, un intento que realizó en 1777 el visitador Areche desde Lima, de levantar esta exención para todo el virreinato, fue tomada como una resolución firme por Jorge Escobedo, gobernador de Potosí y eventualmente sucesor de Areche.

C.M. Por lo que observo en el caso de Potosí, y no es raro para una parte sustancial de la América colonial, es bastante complicado hacer la investigación porque se requiere consultar una serie de fuentes que están en distintos lugares.

E.T. Efectivamente, esto es así, pero tengo que decir francamente que en el caso de Potosí eso también es una ven. taja. Una vez que uno ha trabajado Potosí -y quizá eso explique por qué sigo trabajando Potosi- de una o de otra manera, me parece, uno se envicia; porque, dada la importancia de Potosí (que quizá haya sido aún mayor en el imaginario europeo de la época a la que le correspondía en la realidad), he podido encontrar maravillosos documentos sobre el tema en algunos archivos totalmente inesperados de Francia, Inglaterra, etc. Entonces, esta idea de poder armar un mosaico con notables documentos dispersos es algo cansador, pero por otro lado extremadamente gratificante al final de la jornada.

C.M. Entre las fuentes americanas que nos has señalado están las del archivo de Buenos Aires, las fuentes en el propio Potosí y las fuentes que están en Sucre. Con respecto a Sucre, y más específicamente el Archivo Nacional de Bolivia, creo que la figura de Gunnar Mendoza - que no es muy conocida en México- ha sido de gran importancia para los investigadores andinos, ¿no es así?

E.T. Es de enorme importancia por tres motivos. El primero es que Gunnar Mendoza es un excepcional investigador con una modestia sorprendente. Su obra mayor hay que buscarla en notas a pie de página, prólogos, apéndi- 
ces, en ediciones críticas de fuentes tan notables como los tres tomos de la Historia de Potosi de Arsanz de Urzúa y Vela, o de su edición del diario de un guerrillero de la época de la independencia, etc. Desde ese punto de vista, Mendoza tiene un papel destacadísimo. Por otro lado, todo investigador andino le debe mucho a don Gunnar por la forma en que ha cuidado en situación normalmente precaria su archivo, que él dirige desde hace años, que es el Archivo Nacional y Biblioteca Nacional de Bolivia, ambos en un mismo edificio. Por otra parte, en el caso del Archivo, se cruza su tarea como investigador y su responsabilidad como director del mismo, porque él personalmente ha elaborado índices, documento por documento, de la mayoría de las series coloniales que se encuentran en él. Finalmente, los investigadores andinos que hemos estado en Sucre, somos particularmente deudores de don Gunnar por su capacidad de guía y orientación, tanto en el archivo como en el conjunto de la literatura. Todos los que nos hemos animado, guardamos con enorme gratitud comentarios escritos que nos ha dado don Gunnar a algunos borradores que le hemos sometido en ese archivo donde, diría yo, que nada se pierde y todo se transforma.

C.M. Por último, me parecería interesante saber tu opinión sobre la posibilidad de hacer más estudios de tipo comparativo entre el Alto Perú y Nueva España. ¿Hay algunas vetas o algunas líneas de investigación que te parece podrían desarrollarse con mayor profundidad, que se refieran al siglo XVI, $O$ a los siglos XVII y XVIII?
E.T. Por el hecho obvio de que estamos hablando de colonias de un mismo imperio, creo que las vetas son muy numerosas, y creo que la experiencia de los últimos años nos muestra que las reuniones y los intercambios aparecen como extraordinariamente fructíferos, por la similitud de problemas cuando las preguntas son relativamente parecidas. Y creo que afortunadamente hay una convergencia de preocupaciones, estimuladas precisamente por una vida académica internacional de cierta intensidad. Yo no me atrevería a señalar terrenos particularmente fructíferos para la comparación, pero me parece que casi todos los terrenos, a condición de conseguir un mínimo de fuentes en ambas partes, podrían ser extremadamente importantes. En mi experiencia, tanto los trabajos de minería como los de historia de precios, o los de mercantilización en general, exigen la comparación. También en mis nuevos proyectos actuales de demografía histórica, donde en Los Andes estamos particularmente atrasados, soy enormemente deudor de todas las investigaciones desarrolladas durante años sobre Nueva España, donde toda similitud y todo contraste estimula mi reflexión. Por ello, en el marco de las tareas docentes utilizo en forma permanente la bibliografia novohispana que, no me canso de decirlo, está mucho más adelantada que la andina en tantos aspectos.

C.M. En ese sentido, pero al revés, diría yo que si bien existe un buen cú. mulo de trabajos en la historia novohispana, hay una cierta deficiencia en México en lo que se refiere al conocimien. to de los trabajos sobre la realidad his- 
tórica peruana y altoperuana. Ello no ha sido una preocupación fundamental de los historiadores mexicanos en los últimos años, en parte porque las bibliotecas en México no han adquirido siempre suficientes textos de este origen. Además, me parece que si no se hace un esfuerzo más sostenido de contrastar y comparar distintas realidades -tanto en el plano de la investigación como de la docencia- no se puede lograr un avance muy sustancial en la disciplina. En ese sentido creo que hay un problema medular.

E.T. Sí, creo que has señalado un punto fundamental de carácter instrumental que son las bibliotecas, que es lo que hace que investigadores de fuera de América Latina se sientan más inclinados a las comparaciones por la disponibilidad y fácil acceso al conjunto de la bibliografia. En el caso de América Latina creo que tenemos, sobre todo en el sur, una deficiencia muy grande entre la posibilidad y la necesidad de establecer comparaciones en una escala relativamente grande. No es fácil, por tanto, rastrear un conjunto de trabajos que se producen en otras regiones, como en las que vivimos. $Y$ en el caso peculiar de México, te diría que la tarea se ve especialmente dificultada, paradójicamente por la abundancia de publicaciones y la enorme dificultad del acceso comercial a esas publicaciones. Es decir, si no es gracias a la generosidad de investigadores $o$ instituciones mexicanas sólo accedemos a un libro publicado en México -salvo excepciones como pueden ser las ediciones del Fondo de Cultura Económica- cuando efectivamente visitamos la ciudad de México y nos dedica- mos a explorar librerias, etc. Este es un tema importante, instrumental, ya que en América Latina tenemos una doble limitación: debilidad de las redes de biblioteca y debilidades aún mayores en las redes casi inexistentes de comercialización continental de libros académicos. De ahí, mi experiencia es triste en un sentido, ya que he encontrado que editar en inglés en Estados Unidos garantiza una mejor distribución (por lo menos entre los especialistas del conjunto de América Latina) que editar en español en ninguna parte de la misma región.

C.M. De todas formas, y a pesar de las dificultades que presenta la ineficiencia editorial en la distribución de los libros, pareciera que en los últimos años también existe un esfuerzo y un interés mayor por los investigadores de distintas partes de America Latina en ir a la búsqueda de nuevos temas en regiones poco trabajadas anteriormente. Tu trabajo sobre Potosí me parece que refleja también una tendencia un tanto diferente de la historiografia clásica rioplatense, en tanto que hoy se mueve hacia el Perú, ¿no? Hay antecedentes, pero ¿no dirías que hoy en día existe un mayor interés por parte de los investigadores jóvenes en ese sentido?

E.T. Creo que en el caso de la historia colonial hay una creciente com. prensión de la completa artificialidad en poner límites nacionales en nuestras investigaciones. Obviamente existen problemas materiales importantes y resulta hasta razonable comenzar cualquier investigación con las fuentes de que disponemos más cerca de nuestro lugar habitual de residencia. Pero, 
efectivamente, hay una tendencia a integrar nuestras investigaciones en el conjunto de la producción continental, y creo que esto tiene que ver con una multiplicación de temas, una multiplicación de centros de interés donde en un sentido hay una libertad inédita del investigador. La quiebra de los grandes relatos, los cambios de los paradigmas en los cuales ya nadie se sien. te obligado por imperativos políticos y morales a investigar ciertos temas, genera una circulación un poco errática pero muy fructífera. Así, el joven investigador se orienta hacia el tema que prefiere; luego cada tema parece tener una zona de elección, sea porque ya se ha trabajado y se ha mostrado que esa zona es especialmente fructífera, sea porque tal tema ha sido completamente ignorado en tal área y entonces hay ventajas comparativas en aplicar su trabajo. Creo que sí hay una gran diversificación. Por otro lado, está la internacionalización de la vida académica, donde cada reunión sugiere no sólo temas sino también formas de aborda. je, y esto a su vez multiplica el esfuerzo, el interés por la adecuación entre temas, fuentes, metodologías, etc. En ese sentido, quien se interese por el periodo colonial de Buenos A ires tiene excelentes archivos en la ciudad, aunque tiene una limitación relativa que surge de comparar el tamaño de Buenos Aires en promedio, durante el periodo colonial, con ciudades como Lima, Potosí, ciudad de México, etc. De modo que hay muchos motivos por los cuales uno quisiera -a pesar de las dificultades materiales- desarrollar una investigación que esté centrada en un área que no es la inmediata a la de residencia de uno. Hay también una comprensión, a partir de estos contextos internacionales, del carácter ilumina. dor de la comparación. Entonces, creo que en varios casos, el que ha trabajado en temas de un área determinada, se siente tentado en algún momento a hacer por su propia cuenta la comparación, profundizando también el mis. mo tema en otra área, ¿no? Además, hay una serie de incentivos para ello. Por ejemplo, estoy a cargo del tomo del siglo XviII de la historia de América Latina de la UNESCO, y allí estamos "forzando", por decirlo suavemente, a los autores a que cubran en sus capítulos el conjunto de América Latina durante ese largo siglo xvill. Esto está produciendo buenos resultados y muchos de los autores parecen apreciarlo -una vez superada cierta resistencia inicialy probablemente algunos se envicien y sigan haciendo comparaciones, aunque no se les encargue hacerlas en un futuro. 